\title{
DE LOLA PARA LOLETES: A MULHER NEGRA NAS EMBALAGENS DE COSMÉTICOS CAPILARES
}

\author{
From Lola to Loletes: the black woman in capillary cosmetic packaging
}

De Lola para Loletes: la mujer negra en envases cosméticos capilares

\begin{abstract}
Flávia Mayer dos Santos Souza
Professora do Departamento de Comunicação Social e do Programa de Pós-Graduação em Comunicação e Territorialidades da Universidade Federal do Espírito Santo

flavia.mayer@uol.com.br

Maria Nazareth Bis Pirola

Professora do Departamento de Comunicação Social e do Programa de Pós-Graduação em Comunicação e Territorialidades da Universidade Federal do Espírito Santo

n.pirola@uol.com.br

Juliana Bellia Braga

Mestre em Comunicação e Territorialidades pela Universidade Federal do Espírito Santo julianabbraga@gmail.com
\end{abstract}

\begin{abstract}
Resumo
O movimento de enaltecimento da beleza negra e, consequentemente, dos cabelos crespos e cacheados cresce nos últimos anos fortemente incentivado por interações nas redes sociais digitais. $\mathrm{O}$ mercado de cosméticos capilares reage com o lançamento de itens destinados às mulheres negras e traz embalagens com marcas discursivas que dão pistas de certo diálogo com esse cenário de valorização. Por meio do referencial teórico-metodológico da semiótica discursiva e da semiótica plástica, o artigo analisa quem são e como são construídas as enunciatárias inscritas nas embalagens de cosméticos capilares para a mulher negra, tendo como corpus a linha Meu Cacho Minha Vida, da empresa brasileira Lola Cosmetics. O estudo aponta a compreensão da mulher negra como consumidora, porém são raras as sugestões de sua afirmação identitária mediante a manutenção de uma memória discursiva estereotipada.
\end{abstract}

Palavras-chave: Mulher Negra. Cabelo Crespo. Consumo.

\begin{abstract}
The movement of exaltation of black beauty and, consequently, of curly hair grows in recent years strongly encouraged by the processes of interaction in digital social media. The hair cosmetics market responds with the launch of products aimed at black women, with packaging featuring discursive marks that give hints of a certain dialogue with the movement of appreciation. Through the theoretical-methodological referential of semiotics, this article analyze who are and how are the enunciatees made in the discourses of capillary cosmetic packaging for the black woman, using as a corpus the product line Meu Cacho Minha Vida, from the Brazilian company Lola Cosmetics. The study indicates the understanding of black
\end{abstract}


women as consumers, however there are few suggestions of their identity statement and a stereotyped discursive memory is maintained.

Key words: Black Woman. Black Hair. Consumption.

\section{Resumen}

El movimiento de exaltación de la belleza negra y, en consecuencia, del cabello crespo y rizado ha crecido en los últimos años fuertemente alentado por las interacciones en las redes sociales digitales. El mercado de cosméticos para el cabello reacciona con el lanzamiento de artículos para mujeres negras y trae envases con marcas discursivas que dan pistas para un cierto diálogo con este escenario de valorización. A través del marco teórico-metodológico de la semiótica, el artículo analiza quiénes son y cómo se construyen las enunciatarias inscritas en los envases de cosméticos capilares para la mujer negra, con la línea Meu Cacho Minha Vida, de la compañía brasileña Lola Cosmetics, como su corpus. El estudio apunta la comprensión de la mujer negra como consumidora, pero son raras las sugerencias para su afirmación de identidad al mantener una memoria discursiva estereotipada.

Palabras clave: Mujer negra. Cabello crespo. Consumo.

\section{O CONTEXTO DE VALORIZAÇÃO DA BELEZA NEGRA}

Dados divulgados por meio do relatório Dossiê BrandLab: A revolução dos cachos, produzido pelo Google BrandLab em julho de 2017, demonstram que o interesse por cabelos afro cresceu $309 \%$ no período de 2015 a 2017, e a busca por cabelos cacheados cresceu $232 \%$ entre os anos de 2016 e 2017, ultrapassando, pela primeira vez no Brasil, a pesquisa por cabelos lisos (GOOGLE, 2017, acesso em 01 jun. 2018).

Essas informações têm sintonia com um movimento de valorização da beleza negra e, especialmente, do cabelo crespo, como instrumento identitário. Por intermédio de uma geração constituída por jovens negras que definem a estética negra como marca de um estilo de vida e de pertencimento a um povo, os discursos de enaltecimento do cabelo crespo ganharam espaço significativo nas discussões referentes à constituição de identidades e no combate ao racismo.

Dentro desse debate oriundo das práticas sociais hierárquicas, destaca-se a temática da mulher negra, que assume um papel duplamente inferiorizante. Davis (2017) aponta a questão das mulheres pertencentes às minorias étnicas como sendo afetadas pelas conexões econômica, racial e de gênero. Diferentes modos de opressão sobrepõem-se, compondo uma estrutura de dominação que a coloca em um lugar de subalternidade.

Esses fatores reforçam, além de inúmeras questões sociais, o conflito entre um ideal de beleza branco e eurocêntrico e as expressões do corpo negro, como o cabelo crespo. $\mathrm{O}$ 
enfrentamento contrasta as características do hegemônico e do subalterno, das expressões colonizadoras e colonizadas (HOOKS, 2019).

Segundo Gomes (2003, p. 174), “[...] o corpo é uma linguagem e a cultura escolheu algumas de suas partes como principais veículos de comunicação", sendo o cabelo uma delas. Como elemento visível e destacado do rosto, o cabelo crespo se torna veículo de comunicação e atua como instrumento de resistência estética e política.

Fazem parte desse movimento, por meio das redes sociais digitais, principalmente do YouTube, mulheres negras que encontraram espaço para falar sobre cuidados com os cabelos, sobre produtos capilares específicos e, consequentemente, sobre a autoestima ligada ao enaltecimento dos cabelos crespos e cacheados.

[...] a emergência das redes sociais digitais inseriu os indivíduos, cidadãos e consumidores comuns no ambiente da visibilidade midiática. Dotados de capacidade de comunicação, modalizados pela competência da enunciação, esses sujeitos viabilizam práticas de vida no seu fazer social. Assim, relacionam-se com outros sujeitos, corporações, entidades, no exercício de identidade, publicizando o privado (MARTYNIUK, 2017, p. 18).

O surgimento dos canais de youtubers negras - voltados para assuntos relacionados a cabelo, com abordagem de temas como a autoestima, dicas de produtos, ensinamentos sobre finalizações e tratamentos, e, consequentemente, a possibilidade de assumir os cabelos em sua forma natural - influenciou uma tomada de atenção a esse público, com as marcas vislumbrando a necessidade de ouvir consumidoras que se fazem "[...] nitidamente presentes ao modelarem ativamente os fluxos de mídia” (JENKINS; GREEN; FORD, 2014, p. 25).

Apesar de o enfrentamento ao racismo e as tentativas de reconhecimento da população negra como protagonista de seus discursos constituírem uma luta antiga, as iniciativas na mídia que conferiram certa visibilidade para homens e mulheres negras foram tímidas. Entre elas, está a revista Raça Brasil, por exemplo, surgida nos anos 1990, a primeira revista do país a apresentar conteúdo relacionado à cultura afro-brasileira (REVISTA RAÇA, acesso em 24 jan. 2019). No meio televisivo, somente em 2004, foi lançada Da Cor do Pecado, a primeira trama contemporânea exibida pela $T V$ Globo com uma protagonista negra, interpretada pela atriz Taís Araújo. Antes, foi exibida A Cabana do Pai Tomás, entre os anos de 1969 e 1970, tendo Ruth de Souza como esposa do personagem principal Pai Tomás - escravo negro interpretado pelo ator branco Sérgio Cardoso (MEMÓRIA GLOBO, acesso em 24 jan. 2019) -, havendo divergência no entendimento quanto ao protagonismo da atriz no enredo. 
O cenário caracterizava-se, então, por movimentos isolados em alguns meios de comunicação. A presença rara desse público na mídia foi contraditada pela inserção das mulheres negras em plataformas como o YouTube, onde foi possibilitada a criação de conteúdo e o diálogo com menor presença de filtros, existentes nos meios de comunicação tradicionais.

Essa reconfiguração que se assiste acaba por deslizar para o universo das marcas. No caso do mercado de beleza, observa-se certo deslocamento para um público até então esquecido e o aumento expressivo do número de produtos específicos para cabelos crespos e cacheados em que as marcas, diante do componente sensível do sentido, “[...] subordinam outras narrativas que privilegiam as experiências vividas" (MARTYNIUK, 2017, p. 22) na tentativa de construir um simulacro de proximidade com seus consumidores. Nessa perspectiva, as marcas passam, também, a utilizar canais de youtubers como veículos, por meio do envio de produtos e patrocínio de alguns deles, bem como inauguram seus canais de conteúdo, buscando atingir um público de seguidoras previamente formado.

A partir desse contexto, o presente artigo tem como objetivo compreender, por meio dos preceitos da semiótica discursiva e da semiótica plástica, quem são e como são construídas as enunciatárias inscritas nos discursos das embalagens de produtos cosméticos capilares para a mulher negra.

Após conjunturas de alisamentos, permanentes e relaxamentos, o movimento de enaltecimento dos cabelos crespos surge de modo que os cabelos são apresentados como manifestação cultural, estética e política, uma vez que “[...] a expressão estética negra é inseparável do plano político, do econômico, da urbanização da cidade, dos processos de afirmação étnica e da percepção da diversidade" (GOMES, 2016, p. 49).

O cabelo crespo é considerado elemento essencial na constituição da identidade do indivíduo, faz parte da construção de estereótipos e ocupa lugar central nas discussões e construções de sentimentos de pertença: "Para o negro e a negra o cabelo crespo carrega significados culturais, políticos e sociais importantes e específicos que os classificam e os localizam dentro de um grupo étnico-racial" (GOMES, 2016, p. 46).

As políticas sociais implantadas no Brasil nas últimas décadas contribuíram para que mudanças estruturais na sociedade pudessem ser vistas. Além delas, as políticas afirmativas surgidas, que incluem a população negra como destinatária, são exemplo da indissociabilidade entre as diversas esferas sociais. As políticas de cotas, por exemplo, colocaram o indivíduo 
negro em uma posição de acesso, primeiramente, ao ensino superior, e também o expuseram a uma série de oportunidades de vida às quais ele não teria entrada.

Em matéria divulgada em agosto de 2018, a Folha de São Paulo afirma que em 2017 "[...] as classes A e B receberam 464 mil pessoas que se declaram pretas e pardas" (LIMA, 2018, acesso em 08 fev. 2019). Pode-se considerar que esse dado tem relação com as ações políticas e sociais ocorridas nos últimos anos, que tiveram efeitos no âmbito econômico e, consequentemente, no que se refere aos padrões de consumo.

Nessa perspectiva, não só o reconhecimento da população negra como participante ativa na sociedade, na luta por seus direitos, influenciou uma mudança no que se refere à tomada de atenção do mercado aos seus desejos e às suas necessidades. A percepção das transformações nos padrões de consumo da população negra, para além da aquisição de produtos de subsistência, foi também processo fundamental na adequação das marcas de cosméticos a esse público.

A luta do negro pelo reconhecimento de seus direitos teve, portanto, que incluir a busca por seu reconhecimento como consumidor, visto que [...] não só sua cidadania, mas também sua existência enquanto componente social estava, de certa maneira, atrelada ao seu poder aquisitivo (MARTINS, 2011, p. 57).

Nessa visada, Rocha (1995) explica que o consumo surge como um espaço de realização onde indivíduos e objetos são postos em contato. Em seu campo, ambos adquirem sentido, produzem significações e consequentes distinções sociais. Os objetos determinam a presença ou a ausência de identidade de grupos sociais e indivíduos, definem visões de mundo e estilos de vida, “[...] levam aos consumidores as individualidades e universos simbólicos que a eles foram atribuídos" (ROCHA, 1995, p. 67).

Já para Canclini (1997), o consumo se dá por meio da apropriação dos produtos e de seu uso, em um conjunto de processos socioculturais. Além disso, nele, os desejos são transformados “[...] em demandas e atos socialmente regulados" (CANCLINI, 1997, p. 59).

Em oposição ao raciocínio unilateral de emissor para receptor nas relações de consumo, uma vez que os regimes propostos na contemporaneidade acentuam as conexões e a interatividade, o autor defende que a prática do consumir envolve uma associação mais complexa e menos determinista. Desse modo, o consumo manifesta uma racionalidade sociopolítica interativa. 
Quando vemos a proliferação de objetos e de marcas, de redes de comunicação e de acesso ao consumo, a partir da perspectiva dos movimentos de consumidores e de suas demandas, percebemos que as regras - móveis - da distinção entre os grupos, da expansão educacional e das inovações tecnológicas e da moda também intervêm nestes processos (CANCLINI, 1997, p. 78).

Portanto, a definiçãa de consumo não se reduz à simplificação, nem se resume à noção de consumismo. Para além disso, é possível observar na atualidade “[...] um retorno da religião, uma preocupação com a identidade, com o reconhecimento e a valorização de si, com a aceitação do outro" (LIPOVETSKY, 2000, p. 7). E, na realização dessas práticas, comunicação e consumo se apresentam como um todo indissociável (BACCEGA, 2010).

Sendo a publicidade componente dos processos comunicacionais, Lipovetsky (2000, p. 9) afirma que ela funciona como "cosmético da comunicação", em que o consumidor acolhe uma proposição estetizada, na qual a extensão estética da mercadoria se torna um componente dominante na constituição do objeto, compreendendo design, embalagens e imagens de propaganda (SLATER, 2002).

Desse modo, na tentativa de inserção no mercado, as empresas de cosméticos para cabelos crespos e cacheados buscam a aproximação com o público e utilizam suas embalagens como espaço privilegiado de comunicação que, além das funções de diferenciação, atração, sedução e informação, assumem também o efeito de correspondência entre o produto e a autoimagem do consumidor, remetendo a seu estilo de vida (PEREZ, 2004). Assim, as marcas de cosméticos se atentaram para a necessidade de, em seus processos argumentativos, “[...] divulgar diferenciados olhares de respeito à diversidade” (LEITE, 2018, p. 21).

A análise aqui proposta adota como corpus a linha Meu Cacho Minha Vida, da empresa brasileira Lola Cosmetics. A seleção das embalagens foi realizada por meio da busca de cosméticos para cabelos crespos e cacheados no site da Lola Cosmetics $^{1}$ e na Fanpage ${ }^{2}$ da marca. Pioneira na produção de itens para esse público, a empresa foi uma precursora no Brasil no que se refere a formulações sem ingredientes que prejudicam a hidratação dos cabelos, disseminando assim os conceitos de no-poo ${ }^{3}$ no país. A linha Meu Cacho Minha Vida foi a terceira desenvolvida pela Lola Cosmetics com foco em cabelos crespos e cacheados.

\footnotetext{
${ }^{1}$ Disponível em: http://www.lolacosmetics.com.br

${ }^{2}$ Disponível em: http://www.facebook.com.br/lolacosmetics

${ }^{3}$ Em tradução livre, no-poo significa sem xampu. O principal componente excluído quando se adota a técnica é o sulfato, que retira a oleosidade natural que protege os fios e o couro cabeludo. Também devem ser evitados: silicone, álcool, parabenos e ftalatos, por causarem danos aos cabelos cacheados (MASSEY; BENDER, 2015).
} 
Criada no ano de 2016, conta com os seguintes itens: shampoo; condicionador; jelly gel; creme de pentear, umidificador, ativador e memorizador de cachos (reunidos em um só produto); e máscara hidratante.

\section{A CONSTRUÇÃO DA ENUNCIATÁRIA NAS EMBALAGENS DA LINHA MEU CACHO MINHA VIDA}

Como a semiótica se debruça sobre os efeitos de sentido dos diversos tipos de texto, seu domínio é a linguagem. Essa, por meio da conversão dos sistemas da língua em fala, pelo procedimento de enunciação, projeta no texto as marcas escolhidas pelo enunciador para o parceiro intersubjetivo da comunicação, o enunciatário. Para Fiorin (2011, p. 56), enunciador e enunciatário "Não são o autor e o leitor reais, de carne e osso, mas o autor e o leitor implícitos, ou seja, uma imagem do autor e do leitor construída pelo texto”. Assim, pela análise semiótica, é possível entender a construção dos enunciatários e, com ela, as marcas contextuais históricas, culturais e sociais.

Para estudo das embalagens da linha Meu Cacho Minha Vida (Figura 1), consideramos os rótulos frontais dos frascos. Apesar de os recipientes possuírem rótulos no verso, seus textos verbais apresentam informações técnicas do produto, como ingredientes, modo de uso, precauções, dentre outros, e não há a presença de textos visuais que acrescentem marcas discursivas essenciais para a reflexão a qual se propõe este trabalho.

Figura 1 - Linha Meu Cacho Minha Vida

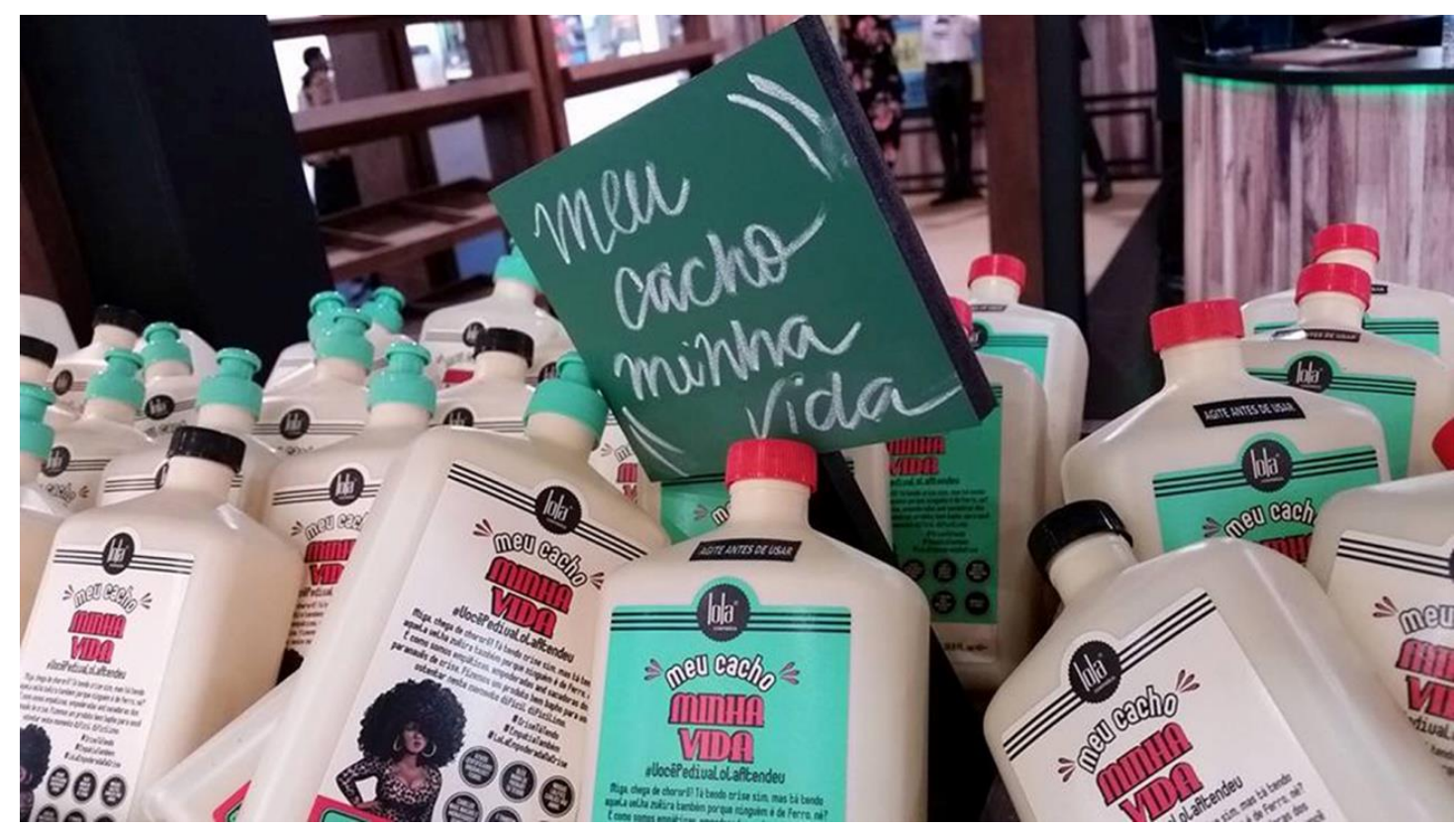

Fonte: Lola Cosmetics(acesso em 03 nov. 2018) 
Segundo a semiótica, o texto "[...] é um objeto de significação e um objeto cultural de comunicação entre sujeitos” (BARROS, 2011, p. 90), resultado da junção entre plano de expressão e plano de conteúdo. Assim, conforme Floch (2001, p. 12), “[...] a semiótica tem como objeto de estudo a relação de pressuposição recíproca (porque só há expressão se houver conteúdo, e não há conteúdo se não houver expressão) entre as duas formas, pois são elas que produzem as diferenças sem as quais não haveria sentido".

Para entendimento do plano de conteúdo, a teoria semiótica recorre ao percurso gerativo de sentido, estabelecido em três etapas: no nível fundamental surge a significação como uma oposição semântica mínima, a determinação dos termos dessa oposição como eufóricos (associados a valores positivos) ou disfóricos (associado a valores negativos); no nível narrativo observamos as ações e transformações de destinadores e sujeitos, e suas buscas pelos valores inscritos nos objetos; no nível discursivo a narrativa é assumida pelo sujeito da enunciação responsável pela produção e pela comunicação do discurso e pelo textoenunciado, assim, as oposições fundamentais, assumidas como valores narrativos, desenvolvem-se sob a forma de temas e, em muitos textos, concretizam-se por meio de figuras (BARROS, 2011).

O plano de expressão é composto por formantes matéricos, cromáticos, eidéticos e topológicos, que comportam entre si função discriminatória para a sua apreensão e estabelecem contrastes que permitem isolar cada formante do todo. Estabelecendo relação com o percurso gerativo de sentido, os elementos do plano de expressão podem corresponder a uma ou mais unidades do plano de conteúdo (OLIVEIRA, 2004).

A dimensão cromática apresenta possibilidades de relações entre as cores
tanto por suas variações (primárias, secundárias, terciárias), como pelos
contrastes estabelecidos (claro vs escuro), bem como tonalidades e
saturação. Já a dimensão eidética convoca formas que podem ser retas vs
curvas, retilíneas vs arredondadas, horizontais vs verticais, dentre outras
combinações em que possam articular no texto plástico. A distribuição das
formas no espaço convoca a dimensão topológica, que pode dispor os
elementos das categorias anteriores em espaços como alto ou baixo, direito
ou esquerdo, central ou periférico. A dimensão matérica depende do tipo de
objeto analisado (SOUZA; PIROLA, 2013, p. 3).

Desse modo, partindo do plano de expressão com o objetivo de estabelecer relação com o plano de conteúdo, no formante matérico, as embalagens são compostas, em seu corpo, de plástico, com a inserção de rótulos em papel adesivo. Como especificidades, os frascos do jelly gel e do creme de pentear possuem tampa com bico dosador. Ademais, a embalagem da máscara hidratante possui, além de formato distinto das outras, um tipo de plástico diferente 
em sua composição; no entanto, são mantidos os elementos que compõem os outros produtos e a harmonia de identidade visual é predominante na linha.

Para a análise do formante topológico consideramos a disposição predominante na maioria dos rótulos das embalagens (Figura 2). Nelas, encontram-se distribuídos, na parte superior, um selo referente à marca Lola Cosmetics, e três linhas pretas que, em conjunto com a barra vermelha, inserida na parte de baixo do adesivo, emolduram o conjunto do rótulo.

Para melhor compreensão da análise dos planos de expressão e conteúdo, seguem transcritos ao lado da imagem do rótulo frontal os textos verbais presentes na embalagem, na sequência em que estão dispostos:

Figura 2 - Embalagem Meu Cacho Minha Vida

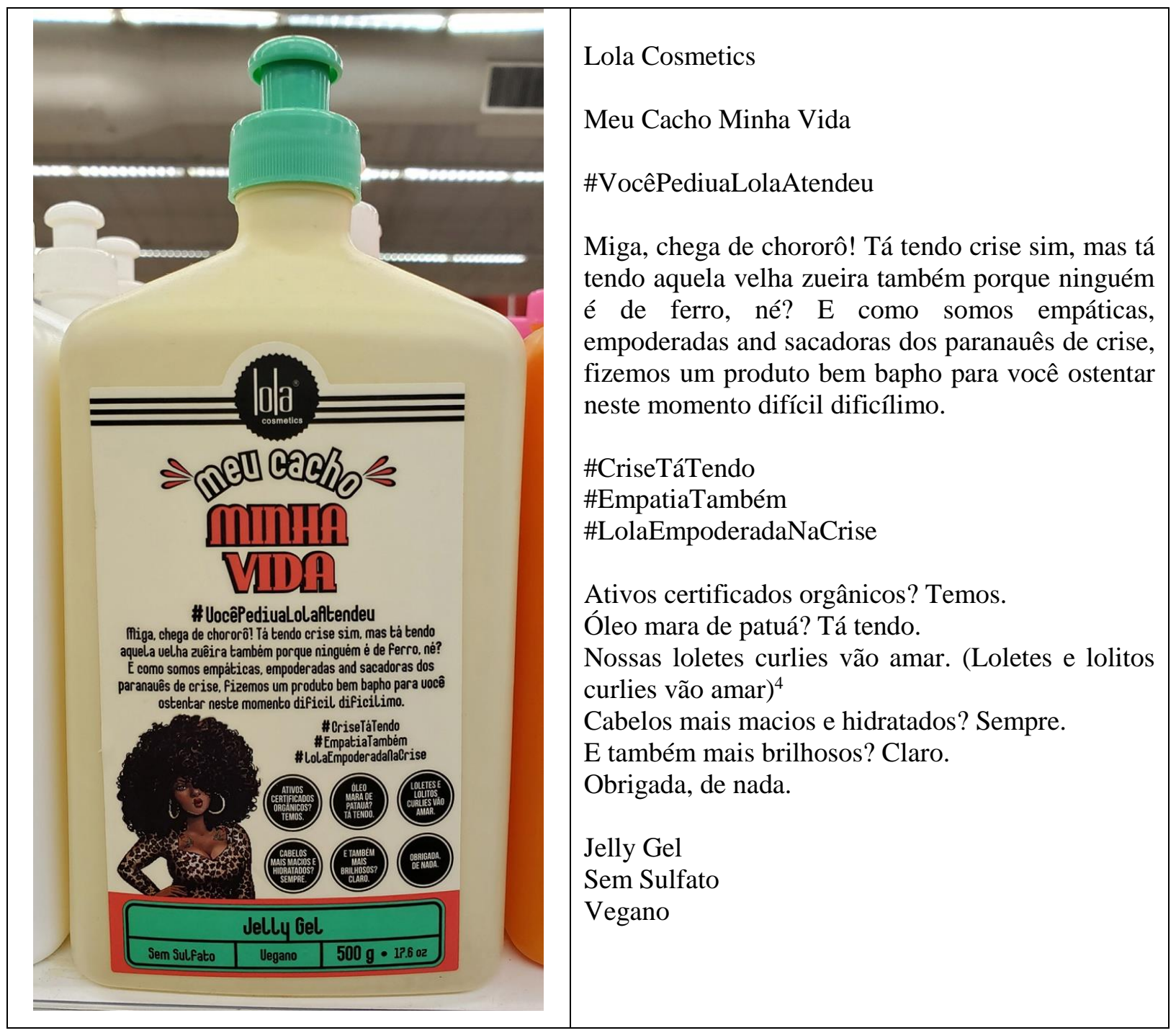

Fonte: Produção própria.

\footnotetext{
${ }^{4}$ Em atualização da embalagem houve também a mudança da frase "nossas loletes curlies vão amar" para "loletes e lolitos curlies vão amar".
} 
Logo abaixo das linhas, ocupando posição de destaque, há a inserção do nome do produto Meu Cacho Minha Vida, remetendo ao programa do Governo Federal Minha Casa Minha Vida (Figura 3), que “[...] oferece condições atrativas para o financiamento de moradias nas áreas urbanas para famílias de baixa renda" e disponibiliza subsídios de acordo com a renda familiar do interessado (CAIXA, acesso em 04 nov. 2018).

Figura 3 - Marca do programa Minha Casa Minha Vida e da linha Meu Cacho Minha Vida
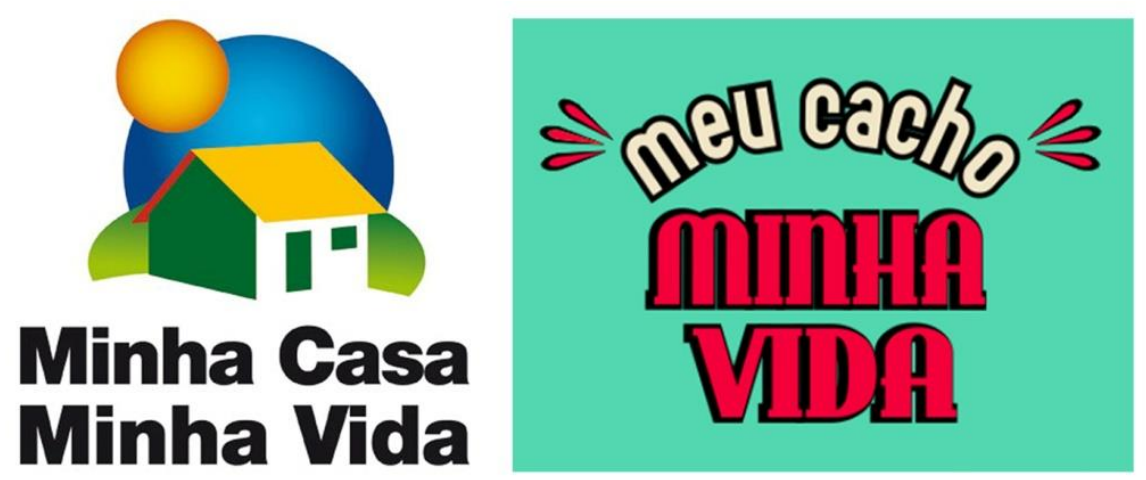

Fonte: Ministério das Cidades (acesso em 19 set. 2019) / Lola Cosmetics (acesso em 20 set. 2019). Adaptado.

O nome Meu Cacho Minha Vida sugere o estabelecimento de uma relação entre as marcas, na qual uma apresenta como valor para seus enunciatários a casa, a segurança do imóvel próprio; e outra, os cachos, com uma linha de produtos com valor mais acessível às consumidoras da Lola Cosmetics. Identifica-se a utilização do recurso da intertextualidade na construção do nome da linha de cosméticos capilares, com o "[...] processo de incorporação de um texto em outro" (BARROS; FIORIN, 1999, p. 35), evocando o nome do programa Minha Casa Minha Vida.

Em texto divulgado à época do lançamento da linha, Dione Vasconcellos, fundadora da empresa, afirma a intenção de oferecer uma linha de produtos com preço reduzido quando comparado a outras linhas da marca: "É com muito orgulho que este kit terá um valor que cabe no bolso mesmo em tempos menos bons. Um valor que permite estarmos com cabelos baphônicos sem para isso sacrificarmos tantas outras coisas" (LOLA COSMETICS, 2016).

Abaixo do nome da linha é possível observar a inserção da expressão “\#VocêPediuaLolaAtendeu”. O uso da hashtag remete à linguagem utilizada pelos usuários das redes sociais digitais. Além disso, o fato de a enunciatária ser construída como alguém que teve seu pedido atendido, produz o efeito de sentido de proximidade e relacionamento entre marca e consumidor, uma vez que "[...] na tentativa de engajar-se às conversas diárias 
dos consumidores, as corporações organizam estratégias de aproximação" (MARTYNIUK, 2017, p. 22).

Em seguida, há a inserção do texto verbal: "Miga, chega de chororô! Tá tendo crise sim, mas tá tendo aquela velha zuêira também porque ninguém é de ferro, né? E como somos empáticas, empoderadas and sacadoras dos paranauês de crise, fizemos um produto bem bapho para você ostentar neste momento difícil dificílimo". Nesse trecho identifica-se a marca Lola doando competência, por meio de seu produto, para a enunciatária, presentificada com o termo "miga".

Abaixo do texto, à esquerda, há a ilustração de uma mulher negra (vide Figura 4), exposta de maneira parcial, apenas de sua cintura para cima. Ao lado dessa mulher se encontra novamente a utilização de recurso das hashtags. São elas: "\#CriseTáTendo", “\#EmpatiaTambém”, “\#LolaEmpoderadanaCrise”.

É possível observar nos trechos a utilização de linguagem informal - com o uso de palavras reduzidas ("miga”, "tá", "né”), de gírias (chororô, zuêira, sacadoras, paranauês, bapho), do termo em inglês “and”-, com o intuito de configurar uma relação de intimidade e familiaridade entre enunciadora e enunciatária. A utilização do termo empatia sugere que a marca se importa com a consumidora de seus produtos. Além disso, o termo crise faz referência ao momento de dificuldade econômica no qual o Brasil se inseria quando do lançamento da linha de cosméticos.

Em uma das inúmeras matérias publicadas pela versão brasileira da página El País em março de 2016, o cenário da economia era apresentado de modo a influenciar diretamente na vida dos brasileiros, sendo determinante na decisão de cortes de gastos e mudanças de hábitos de vida.

O anúncio do tombo de 3,8\% do Produto Interno Bruto (PIB) brasileiro, no ano passado, apenas confirmou o que a população vem sentindo na pele, a economia vai de mal a pior. Segundo os dados do Instituto Brasileiro de Geografia e Estatística (IBGE), o consumo das famílias caiu pelo quarto trimestre seguido e registrou um recuo de consumo de $4 \%$ em relação a 2014. [...] Com a estagnação, a forte disparada dos preços, a alta do desemprego e um dólar cotado na faixa de 4 reais, driblar os efeitos da crise tem exigido bastante jogo de cintura. Para não terminar o mês no vermelho, a maioria dos brasileiros tem mudado os hábitos para fazer o salário sobrar até o final do mês (MENDONÇA, 2016).

As embalagens da linha Meи Cacho Minha Vida trazem não só a marca deste contexto socioeconômico, mas constituem, também, justificativa da criação de um produto capaz de enfrentá-lo. 
Ao lado da mulher negra e abaixo das hashtags estão distribuídos seis círculos com as inscrições "Ativos certificados orgânicos? Temos.”; “Óleo mara de patauá? Tá tendo.”; "Nossas loletes curlies vão amar."; "Cabelos macios e hidratados? Sempre."; "E também mais brilhosos? Claro.”; “Obrigada. De nada.”. A menção de ingredientes específicos, como o óleo de patauá, e de ativos certificados orgânicos aponta para a preocupação da empresa com os componentes de seus produtos, sendo também essa escolha um diferencial para os consumidores. O termo "loletes" traz, para além da relação consumidor/empresa, a relação fã/marca, na qual a consumidora se torna admiradora da Lola Cosmetics.

As frases "Cabelos macios e hidratados?" e "E também mais brilhosos" são as únicas menções diretas de benefícios ao cabelo em todo o rótulo. A utilização de um padrão pergunta/resposta nessas inscrições reforça a interação, o relacionamento construído entre enunciadora e enunciatária, com uma resposta de leitura já antecipada.

Também é possível perceber, por meio dos textos verbais empregados na embalagem, a presentificação da enunciatária em diversos termos como: "você", "miga", "loletes curlies". A utilização de expressões informais se apresenta como mais um recurso que enfatiza a relação de intimidade entre marca e consumidora.

No fim do rótulo há uma faixa em que são inseridos o tipo do produto contido no frasco; as inscrições "Sem Sulfato" e "Vegano" que reforçam a importância da formulação do cosmético sem determinados ingredientes; e informações relativas ao peso do produto.

No formante eidético, percebe-se nas tipologias a tentativa de remontar no rótulo da embalagem um visual retrô, que se define por ser "[...] inspirado nas características formais do estilo do passado, com processos de fabricação atuais" (ROHENKOHL, 2011, p. 151). Contribuem para este entendimento os círculos na parte inferior direita da embalagem, que lembram carimbos, e as formas retangulares, com as bordas arredondadas, tanto nos adesivos colados na embalagem, quanto na moldura das informações técnicas do produto.

Além disso, observa-se que a mulher negra é presentificada por meio de uma ilustração no estilo pin-up (Figura 4), surgido durante a Segunda Guerra Mundial nos Estados Unidos. Assim, percebe-se, mais uma vez, a utilização do intertexto, no entanto, observa-se certa originalidade ao figurativizar uma mulher negra em um estilo que se caracteriza por retratar, em sua maioria, mulheres brancas. 
Figura 4 - Ilustração contida na embalagem Meu Cacho Minha Vida

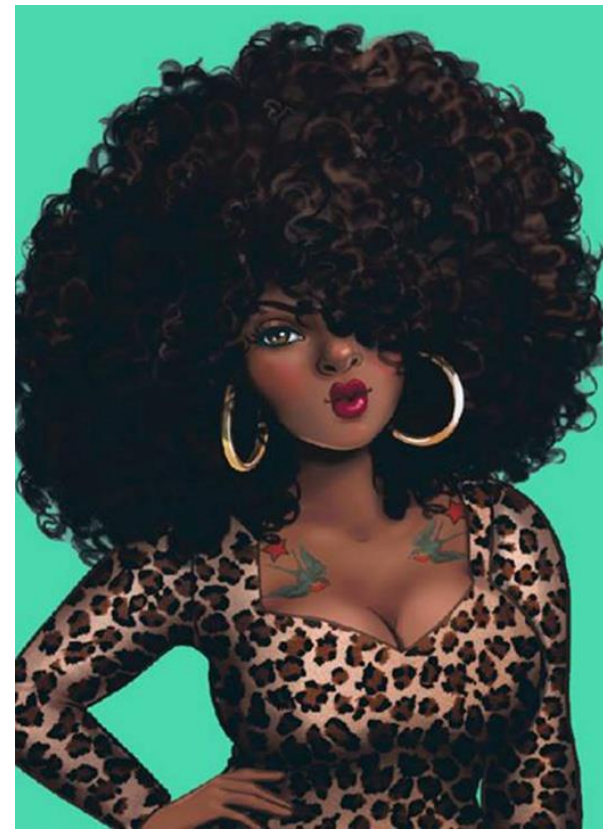

Fonte: Lola Cosmetics (acesso em 03 nov. 2018). Adaptado.

Nessa perspectiva, ao recorrer a esse visual, a marca propõe a construção do sentido de uma trajetória mais antiga, sugerindo que ela já se preocupava com essa mulher e se importava em atender seus anseios.

Para além da estética pin-up, essa mulher apresenta ainda cabelos crespos e volumosos, brincos grandes, rosto maquiado, olhar e postura que inspiram segurança e autoconfiança. Por outro lado, a ponderação sobre a escolha pelo estilo de ilustração, com a utilização de roupas decotadas e formas voluptuosas, permite questionar se ele reforça a objetificação do corpo da mulher negra, hipersexualizado, na constituição de estereótipos.

Segundo a Enciclopédia Intercom de Comunicação (2010, p. 404), o estereótipo “[...] é o processo de sedimentação de conceitos e definições socialmente estabelecidas", e está ligado a características padronizadas, sendo não necessariamente negativas. Entretanto, ao eliminar aspectos particulares de cada indivíduo em detrimento de um padrão fixo e de ideias preconcebidas, essa construção reforça, muitas vezes, a prática do preconceito.

No que se refere ao cromático, nota-se a utilização das cores nas embalagens de modo diferente, contudo, essa variação acontece dentro de uma unidade visual, em que predomina o bege, utilizado no corpo do frasco, uma base neutra para aplicação dos rótulos. A utilização do vermelho se dá na tampa de dois frascos, facilitando a distinção dos produtos, e em alguns detalhes do rótulo. O uso mais marcante ocorre em uma parte do nome da linha: "minha 
vida". Há ainda o marrom no tom de pele da mulher figurativizada na embalagem, construindo, dessa forma, um simulacro da mulher negra, e em sua roupa, uma estampa de onça que, nesse arranjo, reforça o sentido de sedução.

Conforme explicitado anteriormente, a semiótica prevê as análises de textos correlacionando plano de expressão e plano de conteúdo. No que tange a este último, a partir do percurso gerativo de sentido, observamos os níveis discursivo e narrativo.

"Os temas espalham-se pelo texto e são recobertos pelas figuras. A reiteração dos temas e a recorrência das figuras no discurso denominam-se isotopia. A isotopia assegura, graças à idéia de recorrência, a linha sintagmática do discurso e sua coerência semântica" (BARROS, 2005, p.71). A reiteração da crise está presente em diversos trechos dos textos verbais como: "chega de chororô"; "tá tendo crise sim"; "paranauês de crise"; "momento difícil dificílimo"; “\#CriseTáTendo".

A recuperação de um sentido incorporado em uma marca ligada ao financiamento habitacional para pessoas de baixa renda - Minha Casa Minha Vida -, em um momento de dificuldade econômica, também evoca esse tema da crise já no nome da linha.

Segundo Barros (2005, p. 66-67), os percursos temáticos

[...] são constituídos pela recorrência de traços semânticos ou semas, concebidos abstratamente. [...] A recorrência de um tema no discurso depende, assim, da conversão dos sujeitos narrativos em atores que cumprem papéis temáticos.

Com essas premissas, podemos observar no texto verbal do rótulo a recorrência de alguns termos (figurativos e abstratos), tais como: pronomes em primeira pessoa, como "meu", "minha" e "nosso", construindo um efeito de sentido de aproximação; adjetivos, como “empáticas", “empoderadas", "sacadoras"; verbos, como “ostentar", “tá tendo" e "vão amar".

Também se visualiza o uso de uma linguagem de aproximação entre enunciadora e enunciatária, como a utilização da hashtag "VocêPediuaLolaAtendeu" - que projeta a relação "eu-tu" da enunciação. Com isso, a marca, ao inserir verbalmente enunciadora e enunciatária no texto, cria um efeito de aproximação e reitera, pelos fragmentos: "somos empáticas"; “\#EmpatiaTambém”, os valores visados pela enunciatária.

Em "nossas loletes curlies vão amar", em "miga" e "aquela velha zuêira também porque ninguém é de ferro" é possível observar mais recursos de aproximação, familiaridade e intimidade projetados na relação marca e consumidora. Em "empoderadas" e "\#LolaEmpoderadanaCrise" identifica-se a temática do empoderamento contida nas 
embalagens. Em "fizemos um produto bem bapho para você ostentar" explicita-se a projeção de valores vinculados à ostentação. Já a temática capilar aparece de maneira tímida e discreta, fazendo referência aos ativos do produto e aos benefícios oferecidos ao cabelo.

As figuras e temas identificados recobrem uma cadeia de pressuposições lógicas, como parte do esquema narrativo canônico composto por:

[...] sequência da manipulação e do contrato primeiramente, em que o Destinador leva o sujeito a crer, ou não crer, nos valores inscritos nos objetos: ele é a garantia desses valores e em seu nome ele investe o sujeito de um mandato para realizar a ação e se realizar por meio dela. [...] sequência da competência em que o sujeito adquire o desejo, a convicção, o dever, o saber e o poder necessários para agir, em conformidade ou em ruptura com os valores. [...] sequência da ação propriamente dita, a da performance, em que o sujeito realiza, ou não realiza ao contrário, a ação, tendo em vista os valores de referência. [...] sequência, por fim, da sanção, a do retorno do Destinador, em que este reconhece, avalia, recompensa ou pune o autor das ações realizadas (BERTRAND, 2003, p. 41-42, grifos do autor).

Assim, observa-se que a Lola utiliza o simulacro da empatia - recorrente nos textos contidos na embalagem - como estratégia, manipulação, e estabelece um contrato fiduciário de adesão da enunciatária expresso em "VocêPediuaLolaAtendeu", colocando em circulação o sentido de intimidade que conserva com ela.

Na sequência, ao utilizar o contraponto entre os temas crise e empoderamento, como, por exemplo, na escolha pelo uso da hashtag "LolaEmpoderadaNaCrise", a enunciadora coloca a crise como antissujeito e dota a enunciatária de um querer e de um poder vencê-la. A sanção positiva do percurso do destinador manipulador, em que o destinador julgador confirma a performance, está presente em trechos como "Nossas loletes curlies vão amar!” e "Obrigada, de nada".

Desse modo, no nível narrativo, identifica-se que a linha Meu Cacho Minha Vida se constitui como objeto-modal - “[...] cuja aquisição é necessária para realizar a performance principal" (FIORIN, 2011, p. 37) - para que a enunciatária, dotada de competência do poderfazer, saia do estado de disjunção com seu poder aquisitivo, vencendo a crise, e entre em conjunção com o objeto-valor - "[...] cuja obtenção é o fim último de um sujeito" (FIORIN, 2011, p. 37) . 


\section{CONSIDERAÇÕES FINAIS}

Ao refletir sobre quem é a enunciatária e como ela é construída nas embalagens da linha Meu Cacho Minha Vida, é necessário compreender que

[...] o enunciador constrói no discurso todo um dispositivo veridictório, espalha marcas que devem ser encontradas e interpretadas pelo enunciatário. Para escolher as pistas a serem oferecidas, o enunciador considera a relatividade cultural e social da "verdade", sua variação em função do tipo de discurso, além das crenças do enunciatário que vai interpretá-las (BARROS, 2011, p. 63).

Desse modo, as escolhas verbais e visuais utilizadas pela enunciadora Lola Cosmetics apontam uma enunciatária jovem, conectada ao universo das redes sociais digitais, com capacidade para compreender a linguagem marcada por gírias, reduções de palavras e a utilização das hashtags ao longo do texto verbal contido nas embalagens.

Além disso, a marca pressupõe que sua enunciatária não só conheça a Lola Cosmetics, mas que já exista uma relação de intimidade e familiaridade entre elas. O enunciado constrói uma enunciatária que fez um pedido à marca Lola, pedido este que foi atendido com a criação de uma linha de produtos com valor um pouco mais baixo se comparado aos demais fabricados pela empresa e, assim, a marca estreita esses laços, sempre reforçados, pela empatia projetada no texto. Simula colocar-se na posição da consumidora, considerar o contexto da crise e, então, a marca Lola apresenta o produto como solução.

A passagem rápida pela temática capilar em detrimento de outras temáticas também reitera essa familiaridade entre enunciadora e enunciatária. A consumidora da marca já conhece a qualidade dos produtos da Lola e a preocupação da empresa na seleção dos ingredientes, não sendo necessário dar grande destaque a esses aspectos.

A marca Lola cumpre o papel actancial de destinador manipulador e destinador julgador. É quem embala os valores em jogo. Projetada como cuidadora, empática, bem informada, que empodera, incentiva, atende aos pedidos, cumpre um papel temático parecido com o das mães, melhor amiga, conselheira. Uma espécie de salvadora. O nome da marca Lola na topologia superior da embalagem reforça essa ideia de hierarquia, de autoridade.

A projeção da enunciatária é construída com os pronomes meu, minha, você, miga e loletes. Está associada a alguém que precisa de cuidados; sofredora com a crise; frágil; que precisa ser empoderada pela Lola; que tem crises e chora (chororô). Cumpre, assim, um papel temático típico de fã, admiradora, tiete. O termo "Lolete" reforça essa ideia de derivação do nome Lola, assinalando, mais uma vez, o sentido de seguidora. $\mathrm{O}$ recurso figurativo na 
imagem, da ilustração da pin-up na topologia inferior, traz essa ideia, novamente, de hierarquia.

Assim, como uma boa mãe, conselheira, amiga está disponível para resolver problemas, a marca Lola ajuda na liquidação da falta da enunciatária. De disjunção a conjunção, de um não-poder para poder (ter, fazer, ser). E o remédio para a cura desse momento de crise "difícil dificílimo" aparece figurativizado pelo produto da marca.

No entanto, ao trazer o contexto da crise e se colocar no lugar de sua consumidora, utilizando como recursos a empatia e a intimidade, a Lola oferece a linha Meu Cacho Minha Vida como um subsídio, inserindo a enunciatária em um lugar estereotipado, no qual se relaciona a mulher negra com a falta de poder aquisitivo, apostando na fragilidade da enunciatária e construindo para a marca uma posição de autoridade. O visual retrô da embalagem evoca, de certa maneira, uma história da marca, sugere longevidade, contribuindo também para a constituição do lugar de autoridade. Já a fragilidade da mulher negra é construída desde o passado e, neste caso, reforçada pelo contexto, mantendo forte o estereótipo há tanto tempo em circulação.

Além disso, a construção de estereótipos pode ser observada por meio da figurativização da mulher negra, no estilo pin-up, evidenciando suas curvas, destacando o decote, no modo como ela está posta nas embalagens.

Homi Bhabha (2007, p. 105) aponta, se referindo ao discurso colonial, que o estereótipo é "[...] uma forma de conhecimento e identificação que vacila entre o que está sempre 'no lugar', já conhecido, e algo que deve ser ansiosamente repetido [...]”. Nessa perspectiva, ao retomar os efeitos de sentido da marca Minha Casa Minha Vida, por meio do recurso da intertextualidade, as embalagens reforçam modelos e rótulos que acabam por manter processos sociais vigentes. Oscilam entre o reconhecimento da mulher negra e a manutenção de uma memória discursiva estereotipada.

\section{REFERÊNCIAS}

BACCEGA, M. A. Comunicação/educação: relações com o consumo. Importância para a constituição da cidadania. Comunicação, mídia e consumo. São Paulo, v. 7, n. 19, jul. 2010, p. 49-65.

BARROS, D. L. P. Teoria semiótica do texto. São Paulo: Ática, 2011.

BARROS, D. L. P.; FIORIN J. L. Dialogismo, polifonia, intertextualidade. São Paulo: Edusp, 1999. 
BHABHA, H. K. O local da cultura. Belo Horizonte: Editora UFMG, 2007.

BERTRAND, D. Caminhos da semiótica literária. Bauru: EDUSC, 2003.

CAIXA. Minha Casa Minha Vida: Habitação Urbana. Disponível em:

http://www.caixa.gov.br/voce/habitacao/minha-casa-minha-vida/urbana/Paginas/default.aspx . Acesso em: 04 nov. 2018.

CANCLINI, N. G. Consumidores e cidadãos:conflitos multiculturais da globalização. 3. ed. Rio de Janeiro: Ed. UFRJ, 1997.

DAVIS, A. Mulheres, cultura e política. São Paulo: Boitempo, 2017.

ENCICLOPÉDIA INTERCOM DE COMUNICAÇÃO. São Paulo: Sociedade Brasileira de Estudos Interdisciplinares da Comunicação, 2010. Disponível em:

http://www.ciencianasnuvens.com.br/site/wp-content/uploads/2013/07/Enciclopedia-Intercom-deComunica\%C3\%A7\%C3\%A3o.pdf. Acesso em 16 fev. 2019.

FIORIN, J. L. Elementos de análise do discurso. 15. ed. São Paulo: Contexto, 2011.

FLOCH, J. M. Alguns conceitos fundamentais em semiótica geral. Trad. A. D. PILAR.

Documentos de estudo do Centro de Pesquisas Sociossemióticas. São Paulo: Edições CPS, 2001.

GOMES, N. L. Alguns termos e conceitos presentes no debate sobre relações raciais no Brasil: uma breve discussão. In: BRASIL. Educação Anti-racista: caminhos abertos pela Lei federal $n^{\circ}$ 10.639/03. Brasília, MEC, Secretaria de educação continuada e alfabetização e diversidade, 2005.

GOMES, N. L. Corpo e Cabelo como Símbolos da Identidade Negra. In: FIGUEIREDO, A.; CRUZ, C. (org.). Beleza negra: representações sobre o cabelo, o corpo e a identidade das mulheres negras. Cruz das Almas, BA: Ed. UFRB; Belo Horizonte, MG: Fino Traço, 2016.

GOMES, N. L. Educação, identidade negra e formação de professores/as: um olhar sobre o corpo negro e o cabelo crespo. In: Educação e Pesquisa, São Paulo, v. 29, n.1, p. 167-182, jan./jun. 2003.

GOOGLE. Dossiê BrandLab: A Revolução dos Cachos. São Paulo: 2017. Disponível em: https://www.thinkwithgoogle.com/intl/pt-br/advertising-channels/v\%C3\%ADdeo/revolucao-doscachos/. Acesso em 01 jun. 2018.

HOOKS, B. Olhares negros: raça e representação. Tradução: BORGES, S. São Paulo: Elefante, 2019.

JENKINS, H.; GREEN, J.; FORD, S. Cultura da Conexão: criando valor e significado por meio da mídia propagável. Tradução Patrícia Arnaud. São Paulo: Aleph, 2014.

LEITE, F. As brasileiras e a publicidade contraintuitiva: enfrentamento do racismo pela midiatização da imagem de mulheres negras. São Paulo: Alameda, 2018.

LIMA, F. Em retração, classes A e B ganham 464 mil negros. 13 ago. 2018. Folha de S. Paulo. Disponível em: https://www1.folha.uol.com.br/mercado/2018/08/em-retracao-classes-a-e-b-ganham464-mil-negros.shtml. Acesso em 08 fev. 2018.

LIPOVETSKY, Gilles. Sedução, publicidade e pós-modernidade. Revista Famecos, $\mathrm{n}^{\circ} 12$. Porto Alegre, 2000. Disponível em: http://revistaseletronicas.pucrs.br/ojs/index.php/revistafamecos/article/view/3062/2340. Acesso em 25 nov. 2018. 
LOLA COSMETICS. Disponível em: https://lolacosmetics.com.br/. Acesso em 20 set. 2019.

LOLA COSMETICS. Facebook. Disponível em: http://www.facebook.com.br/lolacosmetics. Acesso em: 03 nov. 2018.

MARTINS, C. A. M. A publicidade e o registro branco do Brasil. In: BATISTA, L. L.; LEITE, F. (org.). O negro nos espaços publicitários brasileiros: perspectivas contemporâneas em diálogo. São Paulo: Escola de Comunicação e Artes/USP. 2011. p. 47-60. Disponível em:

http://www.casasemio.com.br/ckfinder/userfiles/files/negropublicidade.pdf. Acesso em 06 jan. 2018.

MARTYNIUK, V. L. "As visões interdisciplinares do consumo no ambiente contemporâneo e as contribuições da semiótica de Greimas para a compreensão desse fenômeno". In: MARTYNIUK, V.L.; OLIVEIRA, A. C. (org.). Sentidos do Consumo: os desafios do cenário contemporâneo à luz da semiótica de Greimas. São Paulo: Estação das Letras e Cores, 2017.

MASSEY, L.; BENDER, M. O manual da garota cacheada: o método curly girl. Tradução Patrícia Azeredo. Rio de Janeiro: Best Seller, 2015.

MEMÓRIA GLOBO. Disponível em: http://memoriaglobo.globo.com/. Acesso em 24 jan. 2019.

MENDONÇA, H. Meu PIB caiu! Brasileiros contam como driblam a recessão. El Pais. Madri, 3 mar. 2016. Disponível em: https://brasil.elpais.com/brasil/2016/03/02/economia/1456935272_932630.html. Acesso em: 28 jul. 2019.

MINISTÉRIO DAS CIDADES. Facebook. Disponível em: https://www.facebook.com/ mincidades/. Acesso em 19 set. 2019.

OLIVEIRA, A. C. As Semioses Pictóricas. In: OLIVEIRA, A. C. (org.). Semiótica plástica. São Paulo: Hacker Editores, 2004.

PEREZ, C. Signos da marca: expressividade e sensorialidade. São Paulo: Thomson, 2004.

REVISTA RAÇA. Disponível em: https://revistaraca.com.br/. Acesso em 24 jan. 2019.

ROCHA, E. P. G. Magia e capitalismo: um estudo antropológico da publicidade. 3. ed. São Paulo: Brasiliense, 1995.

ROHENKOHL, R. A. S. Design retrô: um desafio da contemporaneidade em reconhecimento ao passado. Unoesc \& Ciência - ACSA, Joaçaba, v. 2, n. 2, p. 147-153, jul./dez. 2011.

SLATER, D. Cultura do consumo e modernidade. São Paulo: Nobel, 2002.

SOUZA, F. M. S.; PIROLA, M. N. B. Recortes de um olhar e de um tempo: entre paisagens, cidades, publicidade e consumo. In: OLIVEIRA, A. C.; BOGO, M. B.; ALBUQUERQUE, M. (Org.). Caderno de Discussão do Centro de Pesquisas Sociossemióticas. São Paulo: Edições CPS, v. 22, n. 19, p. 117, dez. 2013. 1 CD-ROM. 
Professora e pesquisadora do Departamento de Comunicação Social e do Programa de PósGraduação em Comunicação e Territorialidades da Universidade Federal do Espírito Santo (UFES). Doutora em Educação pela UFES. Líder do Grupo de Pesquisa Comunicação, Consumo e Semiótica

(UFES/CNPq) e membro do Centro de Pesquisas Sociossemióticas (CPS/PUC/SP/CNPq).

\section{Maria Nazareth Bis Pirola}

Professora e pesquisadora do Departamento de Comunicação Social e do Programa de PósGraduação em Comunicação e Territorialidades da Universidade Federal do Espírito Santo (UFES). Doutora em Educação pela UFES. Líder do Grupo de Pesquisa Comunicação, Consumo e Semiótica (UFES/CNPq) e membro do Centro de Pesquisas Sociossemióticas (CPS/PUC/SP/CNPq).

\section{Juliana Bellia Braga}

Mestre em Comunicação e Territorialidades pela Universidade Federal do Espírito Santo (UFES). Publicitária (Técnica-Administrativa em Educação) da UFES e integrante do Grupo de Pesquisa Comunicação, Consumo e Semiótica (UFES/CNPq).

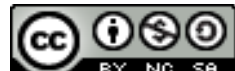

Esta obra está licenciada com uma Licença

Creative Commons Atribuição-NãoComercial-CompartilhaIgual 4.0 Internacional 